\title{
Geociências
}

\section{A turquesa de Itacupim, Pará}

\author{
Marcondes Lima da Costa \\ Dr., Professor, Centro de Geociências/UFPA.E-mail:mlc@ufpa.br \\ Oscar Choque Fernández \\ Dr., Professor, Centro de Geociências/UFPA.E-mail: ochof@ufpa.br \\ Maria Cristina Mota de Toledo \\ Dra., Professora, Instituto de Geociências/USP \\ Camila Maria Passos \\ Instituto de Geociências/USP \\ Patrícia Freitas Pereira \\ Bolsista - Apoio Técnico do CNPq-CG/UFPA
}

\section{Resumo}

$\mathrm{Na}$ ilha de Itacupim, localizada na região costeira do nordeste do Pará, foram encontrados veios de fosfatos de alumínio contendo turquesa, além de quartzo e argilominerais. A ilha é sustentada por espesso perfil laterítico maturo desenvolvido sobre complexo alcalino-ultramáfico mineralizado em apatita. Os veios e vênulas são de espessura centimétrica, normalmente constituídos de wavellita fibro-radial, onde pode ser observada turquesa verde-azulada, em massas subesferolíticas, microcristalinas, intercrescidas com caulinita e oxi-hidróxidos de Mn, além de quartzo. A identificação mineral foi realizada por DRX, microscopia óptica, análises químicas de rocha total, $\mathrm{MEV} / \mathrm{SED}$. Os teores de $\mathrm{CuO}$ são inferiores aos das turquesas em geral, compensados por $\mathrm{Fe}_{2} \mathrm{O}_{3}$ e $\mathrm{ZnO}$. Os subesferolitos de turquesa contêm inúmeras inclusões micrométricas de goyazita ou svanbergita. A ocorrência da turquesa, na forma de veios e vênulas, seu aspecto porcelanado e a conhecida relação desse mineral com ambiente hidrotermal sugerem que a turquesa de Itacupim também seja de origem hidrotermal, reforçada pela sua associação com wavellita, goyazita ou svanbergita, quartzo e argilominerais. Ela não foi encontrada no perfil laterítico. Seu aspecto compacto e sua cor esverdeada abrem perspectivas para seu uso como mineral de gema.

Palavras chave: Turquesa, fosfatos de alumínio, wavellita, apatita, ilha de Itacupim, Amazônia, Brasil.

\begin{abstract}
Veins and veinlets of aluminum phosphates with turquoise occur at the Itacupim Island in the coastal plain northeast the state of Pará. A thick mature lateritic iron crust rich in aluminum phosphates developed an apatite-bearing alkaline-ultramafic complex which constitutes the Island. The veins and veinlets are cmthick, usually constituted by wavellite, fibrous to radialfibrous, with bony or porcelaneous aspect, and can turquoise. Pebbles of these phosphates inside of apatite-bearing ultramafic rocks are very common at the base of the hang wall, and locally form expressive agglomerates. Turquoise forms half spheroids and is bluish-green, microcrystalline, and is intergrown with kaolinite and Mn oxy-hydroxides. The mineral identification was carried out by XRD optic microscopy, chemical analyses by wet methods and by SEM/EDS. The lower $\mathrm{CuO}$ values, in comparison to turquoise elsewhere, are compensated by the higher $\mathrm{Fe}_{2} \mathrm{O}_{3}$ and $\mathrm{ZnO}$. The spheroids display countless inclusions of micrometric goyazite or svanbergite. The turquoise relation to veins and veinlets with wavellite, goyazite or svanbergite, quartz and clay minerals, its porcelaneous aspect and well-known occurrence of turquoise in hydrothermal environment indicate that the Itacupim turquoise was formed by the same mechanism. It doesn't display any clear relationship to laterite profile. The color and compact aspect of this turquoise make it suitable for use as gems.
\end{abstract}

Keywords: Turquoise, aluminum phosphate, apatite, Itacupim island, Amazon region, Brazil. 


\section{Introdução}

A região nordeste do Pará e noroeste do Maranhão caracterizam-se geologicamente por inúmeros depósitos de fosfatos de alumínio associados a corpos lateríticos maturos, que hoje sustentam os relevos do tipo platô (serra do Pirocaua, serra do Piriá, serra do Cansa Perna), morrotes (Jandiá, Bonito, etc.) e ainda algumas ilhas na região costeira paraense (Itacupim, Peito de Moça e Pedra Grande do Gurupi) e maranhense (ilha de Trauira e Tralhoto) (Costa \& Sá, 1980; Costa, 1991). Os fosfatos de alumínio constituem um horizonte situado, caracteristicamente, no topo dos perfis lateríticos, logo abaixo da crosta ferruginosa. Esses fosfatos estão representados principalmente por crandalitagoyazita $\left[\mathrm{CaAl}_{3}\left(\mathrm{PO}_{4}\right)_{2}(\mathrm{OH})_{5} \cdot \mathrm{H}_{2} \mathrm{O}\right]-$ $\left[\mathrm{SrAl}_{3}\left(\mathrm{PO}_{4}\right)_{2}(\mathrm{OH})_{5} \cdot \mathrm{H}_{2} \mathrm{O}\right]$, wardita $\left[\mathrm{NaAl}_{3}\left(\mathrm{PO}_{4}\right)_{2}(\mathrm{OH})_{4} \cdot 2 \mathrm{H}_{2} \mathrm{O}\right]$, senegalita $\left[\mathrm{Al}_{2}\left(\mathrm{PO}_{4}\right)(\mathrm{OH})_{3} \cdot \mathrm{H}_{2} \mathrm{O}\right]$, variscita $\left(\mathrm{AlPO}_{4} \cdot 2 \mathrm{H}_{2} \mathrm{O}\right)$, augelita $\left[\mathrm{Al}_{2}\left(\mathrm{PO}_{4}\right)(\mathrm{OH})_{3}\right]$ e outros fosfatos mais raros, como, por exemplo, os fosfatos de ferro dufrenita $\left[\mathrm{Fe}^{2+} \mathrm{Fe}_{4}{ }^{3+}\left(\mathrm{PO}_{4}\right)_{3}(\mathrm{OH})_{5} .2 \mathrm{H}_{2} \mathrm{O}\right]$, mitridatita $\left[\mathrm{Ca}_{2} \mathrm{Fe}_{3}{ }^{3+}\left(\mathrm{PO}_{4}\right)_{3} \mathrm{O}_{2} .3 \mathrm{H}_{2} \mathrm{O}\right]$, beraunita $\left[\mathrm{Fe}^{2+} \mathrm{Fe}_{5}{ }^{3+}\left(\mathrm{PO}_{4}\right)_{4}(\mathrm{OH})_{5} \cdot 4 \mathrm{H}_{2} \mathrm{O}\right]$, kingsmountita $\left[\left(\mathrm{Ca}, \mathrm{Mn}^{2+}\right)_{4}\left(\mathrm{Fe}^{2+}, \mathrm{Mn}^{2+}\right)\right.$ $\left.\mathrm{Al}_{4}\left(\mathrm{PO}_{4}\right)_{6}(\mathrm{OH})_{4} \cdot 12 \mathrm{H}_{2} \mathrm{O}\right]$ e lazulita $\left(\mathrm{MgAl}_{2}\left(\mathrm{PO}_{4}\right)_{2}(\mathrm{OH})_{2}\right]$, além de hematita, goethita, gibbsita, anatásio e caulinita, tanto na crosta ferruginosa, como no horizonte de fosfatos de alumínio (Costa \& Sá, 1980, Schwab et al., 1989).

Nos fosfatos da Amazônia, a turquesa, um fosfato de alumínio e cobre, foi observada apenas em Maecuru, noroeste do Pará, e como constituinte de alguns seixos, junto às falésias de Itacupim. Na serra do Cansa Perna, também foi encontrado um mineral verde no horizonte de fosfato, porém identificado como variscita com cobre. Recentemente, em 2002, em trabalho de campo na ilha de Itacupim, foram encontrados vários fragmentos e seixos de um mineral esverdeado, com aparência de textura óssea, duros, e identificado como turquesa. Sendo um mineral raro em toda Amazônia e tendo em vista a sua importância gemológica e ainda geológica, como indicador de cobre e fosfatos, e sua aparente relação com os fosfatos de alumínio lateríticos da região, realizou-se o presente trabalho, cujos resultados são discutidos a seguir.

\section{A turquesa}

A turquesa, $\mathrm{Cu}^{2+} \mathrm{Al}_{6}\left(\mathrm{PO}_{4}\right)_{4}$ $(\mathrm{OH})_{8} \cdot 4 \mathrm{H}_{2} \mathrm{O}$, triclínica, $\mathrm{P} \overline{1}$, raramente forma cristais e, quando assim ocorre, os cristais são prismáticos curtos. É geralmente terrosa, devido aos grãos muito finos. Encontra-se em tons de azul-pálido a azul-celeste, verde-azulado a cinzaesverdeado. Na sua composição, podem ocorrer no sítio estrutural $\mathrm{A}$ : $\mathrm{Cu}, \mathrm{Fe}^{2+}$, $\mathrm{Zn}$ e no sítio $\mathrm{B}$ : $\mathrm{Al}, \mathrm{Fe}^{3+}, \mathrm{Cr}^{3+}$. Uma revisão detalhada sobre o grupo da turquesa foi feita recentemente por Foord e Taggart (1998).

Desde os tempos antigos, é apreciada como gema. Seu nome significa pedra turca, pois nos tempos antigos a rota comercial que trazia turquesa para a Europa passava pela Turquia. As melhores turquesas estão no Irã (turquesa persa de Nishapur e Damghan) (Khorassani \& Abedini, 1976), Afeganistão, Austrália, China, Israel, EUA e Tanzânia. As jazidas do Sinai começaram a ser exploradas há mais de 4.000 anos A.C., como pedra

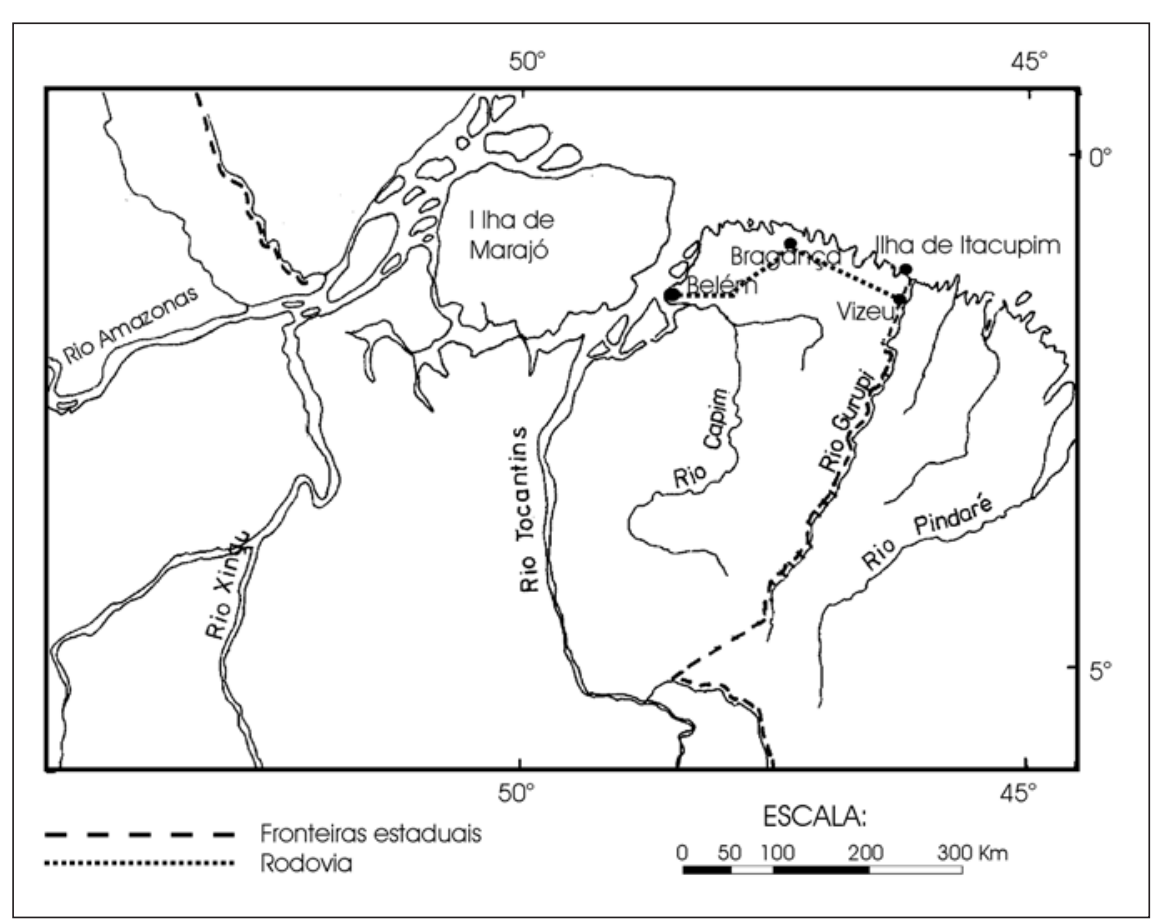

Figura 1 - Mapa de localização da ilha de Itacupim no Estado do Pará.

ornamental, amuleto e ainda maquilagem, posteriormente como corante.

A turquesa é um mineral de origem secundária encontrada como veios e vênulas em rochas vulcânicas ligeiramente alteradas em climas áridos (Klein, 2002). As famosas turquesas da Pérsia (Irã) estão em traquitos junto a Nishapur, da mesma forma que nos EUA. Geralmente ela é encontrada em trançado venulado com vários outros minerais, de tal forma que é mais conhecida como matriz de turquesa. Confunde-se com a variscita azul-esverdeada.

\section{A ilha de Itacupim}

A ilha de Itacupim está situada na costa atlântica do litoral paraense, junto à fronteira com o Estado do Maranhão, próxima a desembocadura do rio Gurupi (Figura 1). Essa região, que é essencialmente plana e baixa, é constituída por manguezais, praias e bancos enormes de areia, berçários de muitas aves, caranguejos, camarões e pescados. Dentro dessa paisagem plana e verdejante, entrecortada por canais de marés e rios, se levanta imponente a ilha de ITACUPIM (ita do tupi-guarani, pedra e cupim, termiteiro - casa de cupins). Ela se alonga 
na direção norte-sul por $1200 \mathrm{~m}$, atinge a largura máxima de 400 m, na direção leste-oeste, e altitude de 60 m, no centro do platô. Seu topo é plano a quase plano, representando, assim, um antigo platô, semelhante aos demais da área continental. Sua borda leste é escarpada, com falésias com dezenas de metros de altura por vezes ainda sob o impacto do mar, com grandes aglomerados de blocos centimétricos a métricos de material ferruginoso tipo casa de cupins (Figura 2) e mesmo acúmulos de seixos da mais variada composição (hematita, goethita, fosfatos de alumínio e rochas verdes). Outras encostas já estão protegidas por manguezais e praias em instalação.

\subsection{A geologia}

A ilha de Itacupim se destaca não somente pelo seu relevo como também pela sua natureza geológica. Trata-se de um complexo alcalino-ultramáfico apatítico, único em toda região, transformado superficialmente em espesso pacote laterítico maturo, rico em fosfatos de alumínio. As rochas verdes, na base das falésias, são observadas quando da baixa-mar, em afloramentos contínuos de dezenas de metros. Elas são de granulometria fina e média, equigranulares a foliadas localmente, formadas por anfibólios, cloritas e muitos minerais opacos, além de apatita, que chega a formar grandes concentrações. Também ocorrem rochas félsicas esverdeadas, duras, formadas dominantemente de feldspatos, além de anfibólios e quartzo. Apresentam muitas fraturas, infiltradas por veios e vênulas de fosfatos, como wavellita, quartzo, mesmo apatita, e, por vezes, turquesa. Esses fosfatos nos veios são quase maciços a fibrosos, duros, de aspecto ósseo ou porcelanado, secionados por vênulas de sucessivas gerações de fosfatos. Veios de extensão decamétrica e espessura centimétrica são freqüentes. Nos acúmulos de fragmentos e seixos, ao longo das falésias, que podem estar parcialmente cobertos por sedimentos lamosos de mangue, encontram-se aqueles constituídos por fosfatos.

Sobre as rochas verdes que afloram na base das falésias, desenvolveu-se espesso perfil laterítico, alcançando os $30 \mathrm{~m}$ de espessura. Em contato com essas rochas, encontra-se um horizonte argiloso de transição com esmectitas e fosfatos de alumínio, sobreposto por espesso horizonte argiloso com caulinita e goethita, além de quartzo, e, em menor quantidade, fosfatos de alumínio. Sobre este se instalou um horizonte de fosfatos de alumínio com alguns metros de espessura, dominado por crandalita-goyazita, goethita, hematita, gibbsita e caulinita. Por último, no topo, estabeleceu-se uma crosta ferruginosa, também com alguns metros de espessura, dura, compacta, cavernosa a pisolítica e nodular, formada por hematita, goethita, os mesmos fosfatos de alumínio e gibbsita. Trata-se de um típico perfil laterítico maturo completo, comparável aos demais da região (Costa, 1991).

\section{A turquesa de Itacupim \\ 4.1 Modo de ocorrência}

A turquesa em Itacupim foi encontrada na forma de mate- rial preenchendo fissuras centiméricas (veios e vênulas) (Figura 3). Esses últimos são normalmente constituídos de quartzo e/ou wavellita ou outros fosfatos de alumínio fibrosos, radiais a sub-radiais. Normalmente estão encaixados nas rochas de cor verde-clara feldspáticas. Associados, encontram-se tam-
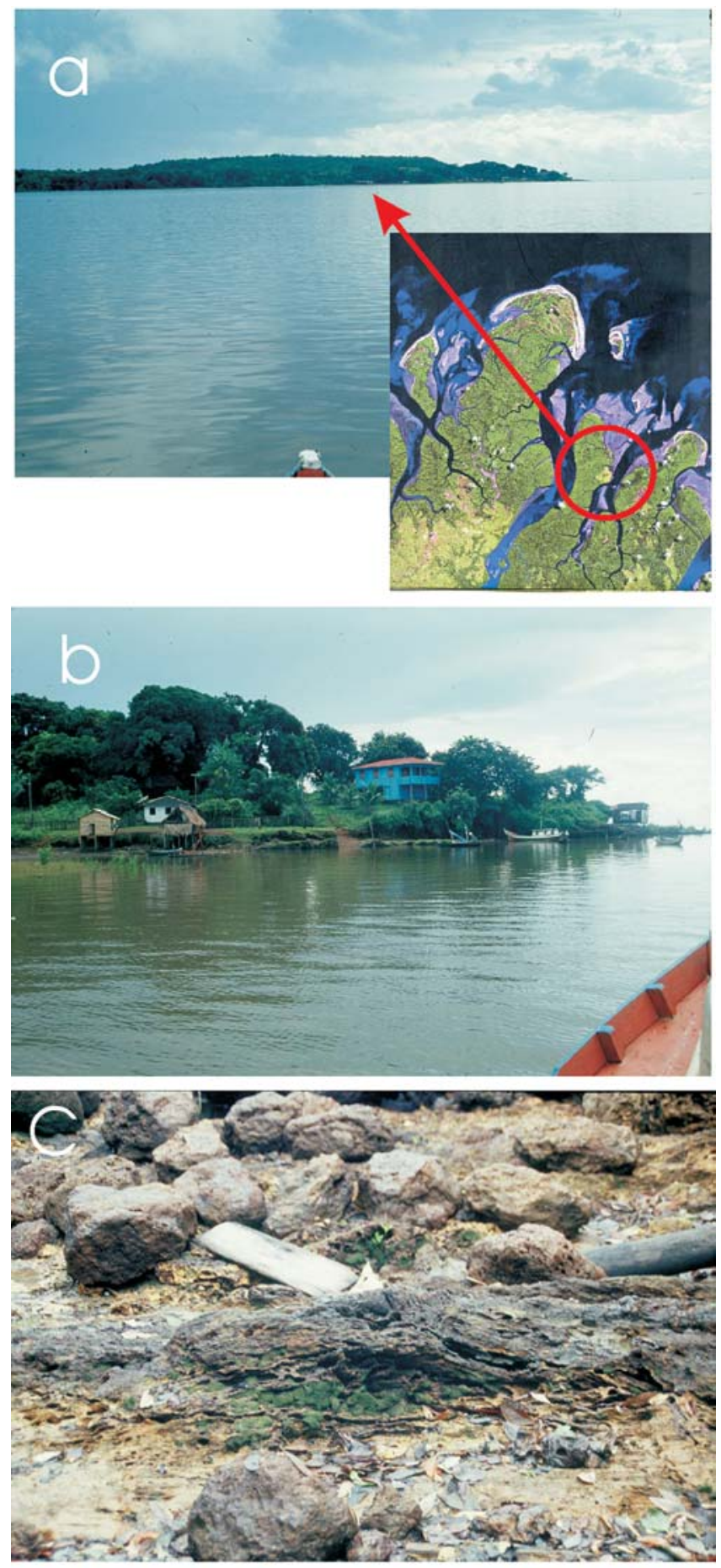

Figura 2 - a) Vista da ilha de Itacupim (pequena área clara no centro da imagem de Satélite) inserida na planície costeira paraense; b) A vila Itacupim ao sul da ilha; c) Exposição de veio de fosfatos goethitizados (marrom) e blocos de rochas verdes e da crosta ferruginosa. 
bém óxi-hidróxidos de manganês microcristalinos, maciços, subesferolíticos ou terrosos e, ainda, argilo-minerais como esmectita e caulinita. $\mathrm{O}$ material como um todo é duro, porcelanado, mesmo aquele com wavellita, que é fibro-radial, por vezes terroso, quando há abundância de argilo-minerais. A turquesa ou matriz de turquesa é de cor verde azulada-clara, entremeada aleatoriamente por material branco de aspecto argiloso a terroso. A turquesa forma sub-esferolitos ou agregados subesféricos, verdeazulados, de 1 a 2 mm de diâmetro, isolados ou agregados, com o material branco argilo-terroso sendo envolvido pela turquesa e vice-versa (Figura 4). Fragmentos e seixos de material com turquesa e wavellita, entre outros, são freqüentes nos cascalhos dos sopés das falésias, que, pela cor clara, destacam-se daqueles marrons-escuros de hematita e goethita, que predominam.

\subsection{Caracterização mineralógica}

A turquesa foi identificada por difração de raios $X$, que mostra grande semelhança com o padrão ICCD (PDF: 6214), referente à turquesa de Campbell Country, EUA. Os difratogramas também confirmam a presença de caulinita. Várias imagens feitas com auxílio de microscopia eletrônica de varredura acoplada a sistema energia dispersiva (MEV/SED) mostraram inclusões micrométricas, cujas análises semiquantitativas obtidas com esse método indicaram tratar-se de material rico em $\mathrm{Sr}, \mathrm{P}$ e Al, aqui interpretado como goyazita ou svanbergita. Interpreta-se, assim, pois estes são os principais fosfatos de alumínio e estrôncio encontrados em ambientes de alteração argílica de rochas ígneas com ou sem hidrotermalismo ou em ambiente supergênico (intemperismo) (Dill, 2001) (Figura 4). Enquanto a série crandalitagoyazita com domínio do membro crandalita $(\mathrm{Ca})$ constitui-se de um mineral freqüente no topo do perfil laterítico de Itacupim e ainda em muitos outros depósitos de fosfatos lateríticos da região nordeste do Pará e Maranhão (Costa \& Sá, 1980), o membro goyazita ou a svanbergita, do grupo da beudantita, não foi encontrado.

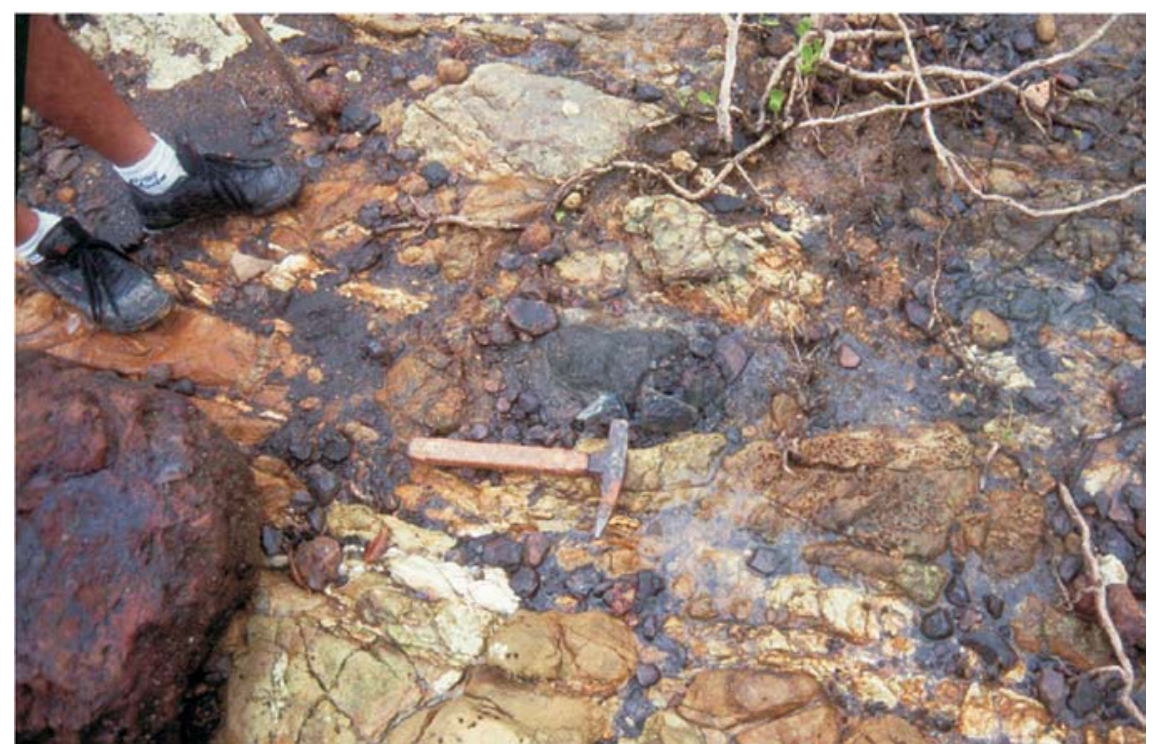

Figura 3 - Veios e vênulas de fosfatos de alumínio com turquesa, apatita, quartzo e argilominerais encravados em rochas verdes.

\subsection{Aspectos microscópicos}

Sob o microscópio óptico, a turquesa forma subesferólitos microcristalinos, sem evidente estrutura fibrosa ou fibroradial, envolvendo ou sendo envolvida pelos argilo-minerais. Massas centimétricas de turquesa são resultantes da agregação de seus inúmeros subesferolitos (Figura 4). As imagens de MEV/SED mostram claramente as inclusões de fosfato de alumínio interpretado como goyazita ou svanbergita (Figura 4), micrométricas, indicação de formação pré-turquesa ou, então, contemporânea. Parte dos argilo-minerais poderia ser hidrotermal ou resultante da alteração intempérica inicial de feldspatos.

\subsection{Composição química}

As análises químicas foram realizadas em amostra total por via úmida (gravimetria, EDTA, volumetria e absorção atômica) nos laboratórios do Centro de Geociências da UFPa. Análises químicas pontuais na massa de fosfatos foram feitas com auxílio de microscopia eletrônica de varredura com sistema de energia dispersiva (MEV/SED) no Museu Paraense Emílio Goeldi. A perda ao fogo da amostra total foi determinda por gravimetria. As análises químicas totais mostram que o material é constituído basica- mente de $\mathrm{CuO}, \mathrm{Fe}_{2} \mathrm{O}_{3}, \mathrm{P}_{2} \mathrm{O}_{5}, \mathrm{Al}_{2} \mathrm{O}_{3}, \mathrm{e} \mathrm{H}_{2} \mathrm{O}$, cujos valores (Tabela 1) são mais compatíveis com aqueles da turquesa de Nishapur, Irã (Khorassani \& Abedini, 1976) e Linch Station, Virginia, EUA (Foord \& Taggart ,1998), exceto para os teores de ferro, que estão mais elevados em Itacupim, ou seja, uma turquesa ferrosa. Foram observadas, ainda, pequenas concentrações de $\mathrm{Zn}$ e também de $\mathrm{Ca}$ e $\mathrm{Na}$, que podem representar as inclusões de goyazita-crandalita ou svanbergita ( $\mathrm{Sr}$ )woodhouseita $(\mathrm{Ca})$. Microanálises químicas obtidas com microscopia eletrônica de varredura com sistema de energia dispersiva se assemelham às análises químicas da turquesa obtidas por via úmida (Tabela 1). Por sua vez, as análises de MEV/SED das inclusões de goyazita ou svanbergita apresentaram os seguintes resultados (\% em peso) $\mathrm{O}: 57,5$; Al:15,8; Si:0,2; P:10; S:1,3; Ca:1,7; Fe:0,6; $\mathrm{Cu}: 0,1$; Sr:11,6 e Ba:1,2 (Total:100), mostrando a presença dominante do membro goyazita ( $\mathrm{Sr}$ ) ou svanbergita, com pequenas proporções de crandalita $(\mathrm{Ca})$ gorceixita $(\mathrm{Ba})$ ou woodhouseita $(\mathrm{Ca}, \mathrm{Ba})$.

\section{Discussões e conclusões}

A turquesa em Itacupim é um mineral encontrado em veios e vênulas e tem características mineralógicas e químicas comparáveis a outras turquesas encon- 

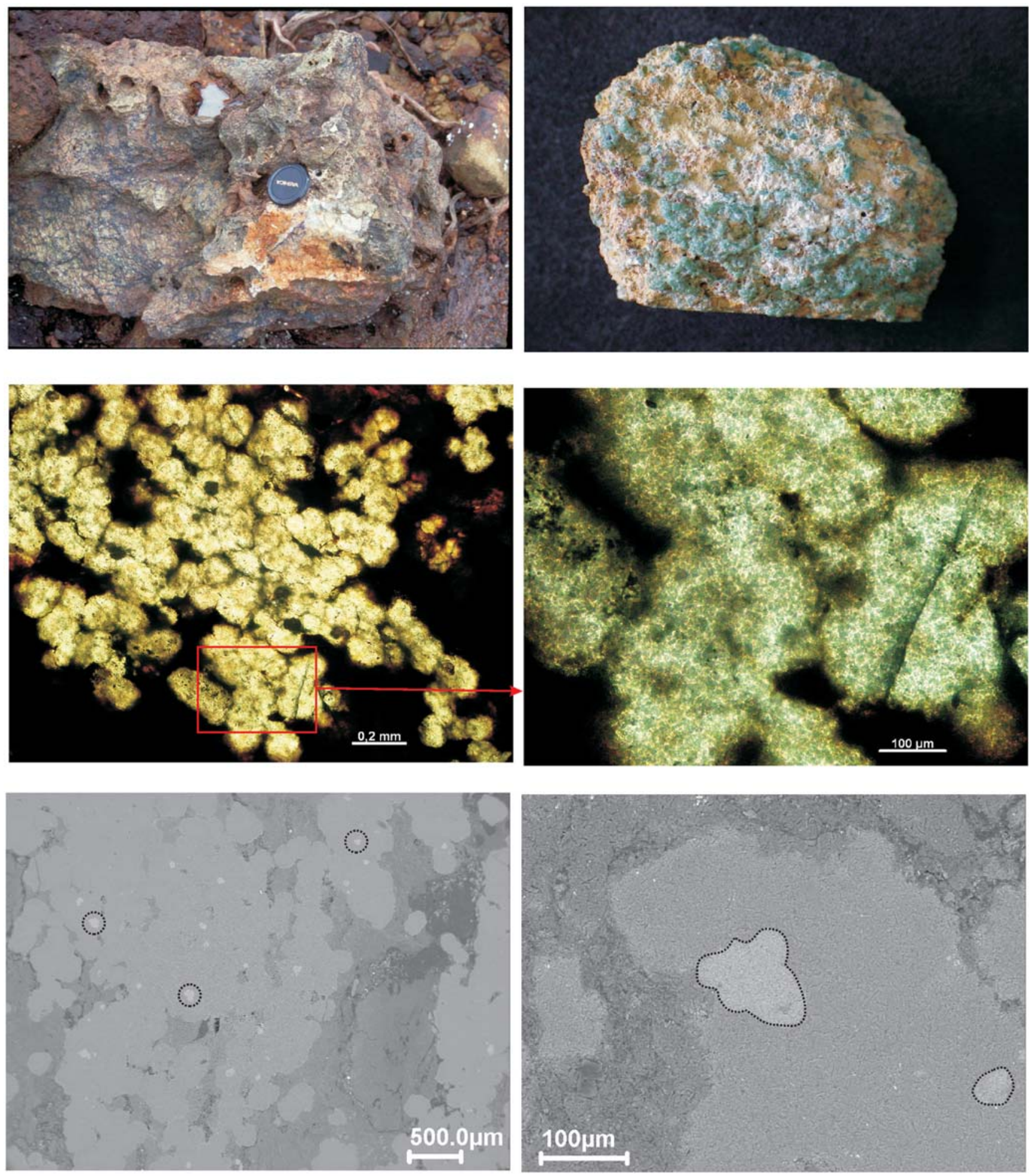

Figura 4 - a) Fragmento de material rico em fosfatos de alumínio com turquesa microvenulada; b) Exemplar de turquesa de veio estudado nesse trabalho; c) A turquesa vista sob microscopia de luz transmitida, polarizadores // mostrando sua feição subesferolítica e relação com os argilominerais (caulinita; esmectita); d) Detalhe da imagem anterior, mas sob polarizadores cruzados; e) Massa subesferolítica de turquesa com inúmeras inclusões de goyazita ou svanbergita (manchas claras, indicadas por círculos pontilhados) vista em imagem de MEV; f) Detalhe das inclusões de goyazita ou svanbergita(mancha clara no centro, linha pontilhada) sob imagem de MEV. 
Tabela 1 - Composição química da turquesa de Itacupim comparada com a de Nishapur, Irã e Linch Station, EUA.

\begin{tabular}{|c|c|c|c|c|c|c|c|c|c|c|}
\hline & CuO & $\mathrm{ZnO}$ & $\mathrm{CaO}$ & $\mathrm{Na}_{2} \mathrm{O}$ & $\mathrm{Al}_{2} \mathrm{O}_{3}$ & $\mathrm{Fe}_{2} \mathrm{O}_{3}$ & $\mathbf{P}_{2} \mathbf{O}_{5}$ & $\mathrm{SiO}_{2}$ & PF & Total \\
\hline Itacupim-Total & 4,55 & 0,31 & 0,22 & 0,37 & 36,54 & 5,45 & 25,80 & 8,74 & 18,74 & 100,72 \\
\hline Itacupim-Microanálises MEV/EDS ${ }^{(1)}$ & 3,10 & & 0,30 & & 38,40 & 1,70 & 33,90 & 4,90 & $17,7^{(1)}$ & 100,00 \\
\hline Itacupim-Microanálises MEV/EDS ${ }^{(2)}$ & 3,10 & & & & 38,20 & 1,30 & 33,20 & 4,50 & $19,7^{(1)}$ & 100,00 \\
\hline Nishapur, Irã ${ }^{(2)}$ & 6,36 & & & & 37,40 & 0,38 & 36,65 & & 18,11 & 98,90 \\
\hline Lynch Station, EUA ${ }^{(3)}$ & 8,81 & 0,14 & & & 37,70 & 0,28 & 34,50 & & 18,20 & 99,63 \\
\hline Teórica & 9,78 & & & & 37,60 & & 34,90 & & 17,72 & 100,00 \\
\hline
\end{tabular}

(1) A perda ao fogo (PF) foi obtida por diferença após a distribuição dos valores obtidos para oxigênio nos diferentes óxidos dos metais. Para esse cálculo foi desprezado o hidrogênio.

(2) Nishapur, sky blue, Khorasani \& Abedini, 1976.

(3) Linch Station, Virginia, EUA (Foord \& Taggart ,1998).

tradas em outras partes do mundo. Embora os afloramentos com turquesa em Itacupim estejam situados na base do perfil de alteração intempérica laterítica, ou seja, nos primeiros estágios de intemperismo (zona de transição), em contato com a rocha sã, a turquesa investigada não se apresenta como mineral intempérico. Ela tem aspecto porcelanado, da mesma forma que a wavellita, está associada com caulinita e esmectita, também compacta, e forma veios e vênulas, provavelmente relacionados aos eventos deformacionais, que fraturaram a rocha encaixante. Fosfatos de alumínio do supergrupo da alunita com as características acima são encontrados principalmente em rochas ígneas que sofreram alteração argílica com ou sem mineralização hidrotermal (Dill, 2001)em ambiente vulcânico ou subvulcãnico. A presença de inclusões micrométricas de goyazita ou de svanbergita na turquesa também sugere que esse mineral possa ser préintempérico. Goyazita ou svanbergita são descritos em algumas regiões como intempéricos, sendo mais comuns em rochas ígneas argilizadas (Dill, 2001). Seus dados termodinâmicos mostram que sua formação é favorecida em condições hidrotermais (Schwab et al., 1991 e 1993). $\mathrm{Na}$ região laterítica do Gurupi, rica em fosfatos de alumínio, domina a série crandalita-goyazita, predominando o membro cálcico. Nos mais diferentes depósitos de turquesa conhecidos no mundo ela é reportada em rochas ligeiramente altera- das, porém essa alteração está relacionada mais ao ambiente semi-árido ou desértico ou mesmo à argilização hidrotermal, promovida por atividades vulcânicas tardias (Klein, 2002). A presença de turquesa em Itacupim sugere que as rochas do complexo ultramáfico-alcalino contêm, pelo menos localmente, minerais com cobre, possivelmente sulfetos, que foram remobilizados e reprecipitados ao longo de zonas de fraturas, em ambiente de natureza argílica, possivelmente hidrotermal, levando à formação de fosfatos de alumínio como a turquesa, entre outros (Dill, 2001). A fonte de fósforo foi a apatita, abundante no complexo. A ocorrência abre perspectivas para a explotação de turquesa gemológica.

\section{Agradecimentos}

Ao $\mathrm{CNPq}$, pelo apoio financeiro através de projeto de pesquisa, bolsa de produtividade em pesquisa; a FAPESP, pelo apoio financeiro a projeto de pesquisa e bolsa de iniciação científica; a Henrique Diniz, pelo apoio nos trabalhos de campo, e a Natalino Valente Moreira de Siqueira, pelo apoio às análises químicas totais; aos habitantes de Itacupim, pela amabilidade, em especial das famílias José Arnaldo Lopes, Celma Barbosa e filha Suely e Antônio Cairara, Maria da Conceição e seus filhos Jucilene, Jucinéia e Antônio.

\section{Referências bibliográficas}

COSTA, M.L. Aspectos geológicos dos lateritos da Amazônia. Revista Brasileira de Geociências, v.21, n.2, p.146-160, 1991.

COSTA, M.L., SÁ, J.H.S. Os fosfatos lateríticos da Amazônia Oriental: geologia, mineralogia, geoquímica e correlação com as bauxitas da Amazônia. In: CONGR. BRAS. GEOL., 31, 1980. Santa Catarina. Anais... Santa Catarina: SBG, 1980. v. 3, p.1459-72.

DILL, H.G. The geology of aluminium phosphates and sulphates of the alunite group minerals: a review. Earth-Sciences, 53, p.35-93, 2001.

FOORD, E.E., TAGGART, J.E. A reexamination of the turquoise group: the mineral aheylite, planerite (redefined), turquoise and coeruleolactite. Mineralogical Magazine, v.62, n.1, p.93-112, 1998.

KHORASSANI, A., ABEDINI, M. A new study of turquoise from Iran. Mineralogical Magazine, v.40, p. 640-642, 1976.

KLEIN, C. Mineral Science (after J. D. Dana). New York, John Wiley \& Sons, 2002. 642p.

SCHWAB, R.G., HEROLD, H. COSTA, M.L., OLIVEIRA, N.P. The formation of aluminous phosphates trhough lateritic weathering. In: Products and deposits. Theophastrus Publications, Alhen, v. 2, p. 369-386. 1989.

SCHWAB, R.G., CHRISTIAN, G., HEROLD, H., OLIVEIRA, N.P. Compounds of the crandallite type: synthesis and properties of pure ( $\mathrm{Ca}, \mathrm{Sr}, \mathrm{Ba}, \mathrm{Pb}, \mathrm{La}, \mathrm{Ce}$ to $\mathrm{Eu})$ arsenocrandallites. N.Jb.Miner.Mh., H.3, p. 97-112, 1991.

SCHWAB, R.G., CHRISTIAN, G., HEROLD, H., OLIVEIRA, N.P. Compounds of the crandallite type: thermodynamic properties of $\mathrm{Ca}, \mathrm{Sr}, \mathrm{Ba}, \mathrm{Pb}, \mathrm{La}, \mathrm{Ce}$ to Gd-phosphates and arsenates. N.Jb.Miner.Mh., H.12, p. 551-568, 1993.

Artigo recebido em 10/12/2003 e aprovado em $08 / 11 / 2004$. 